\title{
Abundance of minerals in the phyllosilicate-rich units on Mars ${ }^{\star}$
}

\author{
F. Poulet ${ }^{1}$, N. Mangold ${ }^{2}$, D. Loizeau ${ }^{2}$, J.-P. Bibring ${ }^{1}$, Y. Langevin ${ }^{1}$, J. Michalski ${ }^{1}$, and B. Gondet ${ }^{1}$ \\ 1 Institut d'Astrophysique Spatiale (IAS), Bâtiment 121, 91405 Orsay Cedex, France \\ e-mail: francois.poulet@ias.u-psud.fr \\ 2 Interactions et Dynamique des Environnement de Surface (IDES), Bâtiment 509, 91405 Orsay Cedex, France
}

Received 7 May 2008 / Accepted 24 June 2008

\begin{abstract}
Context. Phyllosilicates were definitely identified on Mars by the OMEGA (Observatoire pour la Minéralogie, l'Eau, les Glaces et l'Activité) instrument onboard the Mars Express spacecraft. The identification, characterization, and mapping of deposits of these minerals hold clues to the potential past habitability. They also constitute a key element in planning for future landing sites.

Aims. To infer the environmental conditions that existed at the time of the formation of these minerals, it is critical to determine if and how the composition of the deposits vary in space and time.

Methods. We applied radiative transfer modeling to the OMEGA reflectance spectra to derive the modal mineralogy (mineral abundances) of some phyllosilicate-rich deposits.

Results. In many outcrops, including the large areas in Nili Fossae, the surface mineralogy is dominated by primary non-altered minerals, with minor fractions of phyllosilicates. These assemblages could result from hydrothermal alteration. By contrast, deposits in the Mawrth Vallis region exhibit a large content of hydrated phyllosilicates, which suggests that the rocks may be mature sedimentary rocks or altered volcanics. Evidence of alteration resulting from metamorphism due to an impact is reported in the central peak of a crater.
\end{abstract}

Key words. planets and satellites: general

\section{Introduction}

Reflectance spectra obtained by the OMEGA instrument on the Mars Express orbiter reveal the presence of $\mathrm{Al}-\mathrm{OH}$ and $\mathrm{Fe} / \mathrm{Mg}-\mathrm{OH}$ bearing minerals, with $\mathrm{Fe} / \mathrm{Mg}$-phyllosilicates the most common (Poulet et al. 2005). The first results of the Compact Reconnaissance Imaging (CRISM) spectrometer aboard the Mars Reconnaissance Orbiter consistently indicate that the alteration products of $\mathrm{Fe} / \mathrm{Mg}$ mafic minerals are spatially over-represented compared to Al-rich ones, such as plagioclase (Mustard et al. 2008). OMEGA and CRISM global mappings show that phyllosilicates are widespread, with the most extensive phyllosilicate-rich regions located in Mawrth Vallis and Nili Fossae and associated with a range of geomorphic features that are essentially restricted to ancient terrains (Poulet et al. 2005; Mustard et al. 2008). Because the phyllosilicate-bearing deposits are unique and critical records of the past aqueous activity on Mars, one needs to understand how they formed; e.g., did they form on the surface in concert with an active hydrologic system or at depth in a hydrothermal or warm, wet crust, or did impacts play a role? A key constraint of the formation process is in the precise mineralogical composition of the terrains keeping a record of the alteration. We thus derive the modal mineralogy of the major phyllosilicate-rich deposits identified by OMEGA by using a radiative transfer model, and discuss the differences in terms of phyllosilicate formation processes.

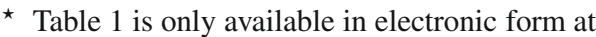
http: //www . aanda.org

\section{Data selection and modeling method}

A representative set of phyllosilicate-rich terrains was selected for analysis in this work (Table 1, available in electronic form, which contains the location and the modal abundances of the studied deposits). We focus our analysis on the deposits associated with exposed and eroded surfaces having moderate to high thermal inertia as previously reported in Poulet et al. (2005), Loizeau et al. (2007), and Mangold et al. (2007). Each analyzed spectrum corresponds to a single OMEGA pixel $(0.6$ to $3 \mathrm{~km}$ in size), for which the spectral signatures of phyllosilicates are among the strongest within the outcrop studied. In addition, most of the spots are specifically selected using high-resolution visible images to include surfaces inside uniform large phyllosilicaterich deposits without visible aeolian features. The composition will correspond to an average of a geologic unit on the OMEGA pixel scale, not excluding individual layers to display variations.

Standard processing approaches have been used to convert OMEGA data from instrument units to Lambertian, atmospherically corrected reflectance. One of the significant challenges for the use of near-infrared (NIR) reflectance spectroscopy is the conversion of band depth absorptions identified in the reflectance spectra to mineral abundances. Modal mineralogy is derived here using a nonlinear unmixing modeling based on the radiative transfer model of Shkuratov et al. (1999). This model simulates the reflectance of a particulate surface (also referred to as an intimate mixture) from the complex indices of refraction of each component. The scattering theory of Shkuratov is also used to iteratively determine the imaginary index of refraction of 
various materials from the laboratory reflectance spectra (Poulet \& Erard 2004; Roush et al. 2007). Poulet et al. (2002) show its degree of realism and efficiency relative to other scattering models and, in particular, to the Hapke model and its derivatives. This model has been validated on laboratory and natural mafic mineral samples (Poulet \& Erard 2004). However, natural rock surfaces, especially those chemically altered and consisting of a variety of crystalline and poorly crystalline secondary phases, could be more complicated systems with more variables than laboratory controlled mineral mixtures. However, we will see that a restricted number of five end-members at most can provide satisfactory fits. Moreover, the model has been successfully applied to spectra of a variety of planetary surfaces including the Martian surface (e.g. Poulet et al. 2002, 2003; Arvidson et al. 2007). These different studies and tests lead us to feel confident in our modeling approach.

For each OMEGA spectrum, the model must reproduce the shape and depth of each absorption band, the shape of the continuum, as well as the absolute value of the Lambertian albedo reflectance. A free parameter, which does not affect the absorption features, is also used to adjust the continuum spectral slope so as to account for the contribution of aerosols and/or photometric effects. The spectra are fitted in the $0.99-2.50 \mu \mathrm{m}$ wavelength range using a simplex minimization algorithm. The quality of the fit is evaluated by a visual, qualitative comparison of the model and measured spectra, and quantified by the value of the residual mean squared (rms).

The selection of minerals to be included (through their complex indices of refraction) in the modeling as end-members is critical. We started considering a very wide variety of potential minerals, and only excluded those for which diagnostic absorption features were not present in OMEGA spectra. For example, zeolites were excluded because they are characterized by a strong plateau-shape absorption starting at 2.35$2.40 \mu \mathrm{m}$, which is not observed in the OMEGA spectra of the sites analyzed. The set of minerals used in the modeling includes unaltered silicates and secondary water/OH bearing minerals. Among the phyllosilicates, the dioctahedral Fe/Mg/Alsmectites have previously been proposed as components of the OMEGA spectra (Poulet et al. 2005); other phyllosilicates (illite, saponite, chamosite, chlorite, hisingerite and kaolinite) that are representative of different levels of aqueous alteration are also considered. Iron hydroxides, such as ferrihydrite, are included as potential end-members because their spectrum exhibits a ferric signature coupled to a shallow $1.9 \mu \mathrm{m}$ band due to water combination overtones, which are qualitatively similar to features observed in the relevant Martian spectra. Conversely, we exclude other hydroxides such as goethite, gibbsite, bohmite, and diaspore, that exhibit strong features not present in the analyzed OMEGA spectra.

The absorption features of OMEGA spectra of phyllosilicate-rich terrains are much shallower than those of spectra of pure phyllosilicates (Fig. 1A). The surface exposure to the Martian environment and grain size effect have been shown to be unable to account for this reduced spectral contrast (Cloutis et al. 2007, 2008; Cooper \& Mustard 1999). Admixture of non-phyllosilicate anhydrous components is therefore required to account for it. Primary minerals such as plagioclase, pyroxenes, and olivines are thus considered as potential endmembers: when a phyllosilicate is intimately mixed with the NIR spectrally featureless plagioclase, the specific $\mathrm{H} 2 \mathrm{O}, \mathrm{OH}$, and cation-OH bands are significantly decreased. The Mars Global Surveyor/Thermal Emission Spectrometer characterization of phyllosilicate-rich terrains, including Mawrth Vallis,
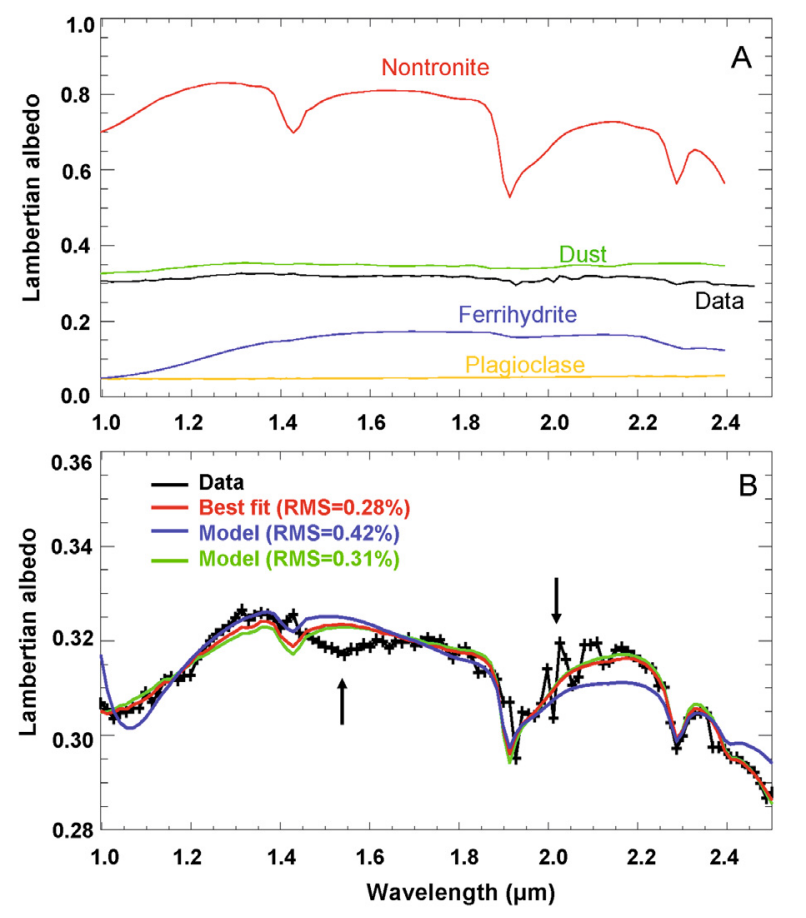

Fig. 1. Fitting procedure for one spectrum that exhibits an $\mathrm{Fe}-\mathrm{OH}$ feature at $2.29 \mu \mathrm{m}$ (spot MV2). A) Spectra of the mineral end-members used in the modeling compared to the OMEGA data spectrum (black line) to be modeled. The end-member spectra correspond to spectra of pure minerals except for the plagioclase spectrum, for which submicrometer-sized oxide grains are embedded inside the plagioclase matrix as described in Poulet \& Erard (2004). B) The data spectrum (black line) is compared to three models. The best fit (red line) corresponds to a total fraction of $75 \%$ of hydrated minerals (here, nontronite and ferrihydrite). If the total fraction of hydrated minerals is forced to be diminished by $10 \%$ (blue spectrum) or increased by $10 \%$ (green spectrum), the fit is significantly degraded. The discrepancies observed in the 1.4-1.55 $\mu \mathrm{m}$ (see arrow) result from an instrumental artifact that depends on the flux received by the instrument (Langevin et al. 2007). This partly explains the lack of the $1.4 \mu \mathrm{m}$ band due to presence of $\mathrm{OH}$. The spikes in the 1.9-2.1 $\mu \mathrm{m}$ region (see arrow) can be attributed to the atmospheric removal (CO2 gas).

which exhibits feldspars and/or pyroxenes (Michalski et al. 2007), further supports the inclusion of these minerals in our modeling. However, from a spectral standpoint, other spectrally almost featureless components, such as amorphous silica, could be substituted or added to the plagioclase component. In addition to these minerals, we included in the modeling, species, which also appear almost featureless in the spectral domain of our analysis but contribute to the overall shape and level of the continuum. In this context, we introduced iron oxides and Martian dust, as identified in bright Mars spectra.

\section{Results}

We have modeled spectra representative of several outcrops in Marwth Vallis, and summarized the best fits to the derived mineralogical composition in Table 1. A restricted set of four endmembers gives satisfactory fits for most sites with rms errors lower than 0.0030: a phyllosilicate, with nontronite as the most common mineral, to account for the $\mathrm{H} 2 \mathrm{O}, \mathrm{OH}$ and metal-OH absorption bands, the hydroxide ferrihydrite, a plagioclase mineral (labradorite), and the Martian dust component. As shown in Fig. 1, the phyllosilicate bands are visually well reproduced and the rms is lower than 0.0030 , which indicates that all spectrally 

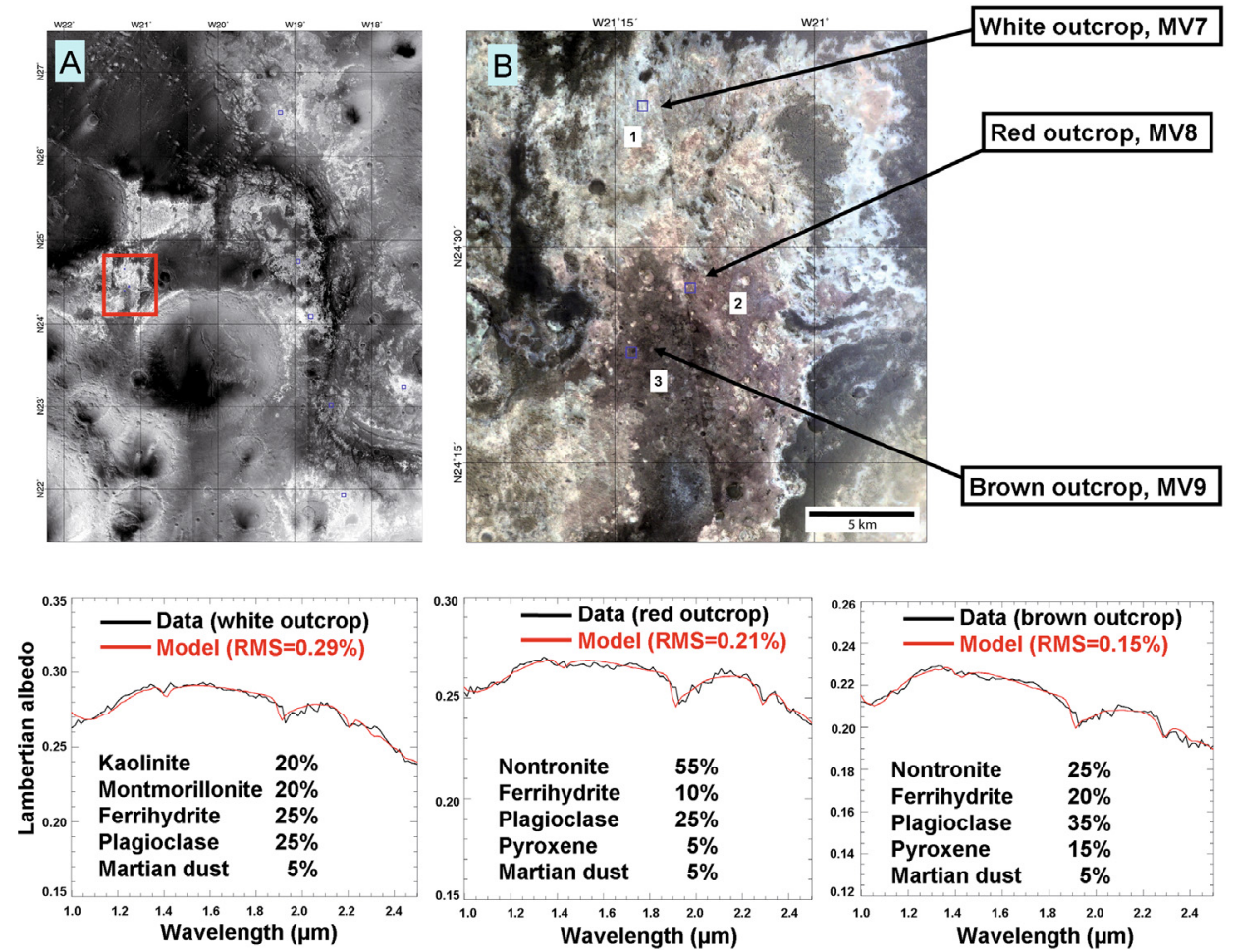

Fig. 2. A) High-Resolution Stereo Camera (HRSC) mosaic of the region of Mawrth Vallis. Blue squares indicate the location of MV1-6 spots. A box delineates an enlarged portion (red) of the HRSC color RGB image shown in (B). B) Three stratigraphically distinct units can be identified: unit 1) upper whitish bright, unit 2) middle reddish, and unit 3) lower brown. Locations for which OMEGA spectra were extracted and then modeled are also indicated by the blue pixels (real sizes). The fit results are shown for each spot.

important components are likely to be present. The OMEGAderived abundances of phyllosilicates are estimated to be accurate to about $+/-10 \%$ (Fig. 1 ).

In Mawrth Vallis, the derived abundance of nontronite (from $20 \%$ to $65 \%$ depending on the spots) is correlated to the band depth at $2.29 \mu \mathrm{m}$ as is indicative of the $\mathrm{Fe}-\mathrm{OH}$ group, further demonstrating that the variation in the abundance does not result from an artifact of the modeling, but is real. In the region west of the mouth of Mawrth Vallis (Fig. 2), the modeling of selected spots (MV7-9) reveals different modal compositions associated with stratigraphically distinct outcrops of different visible colors reported previously (Loizeau et al. 2008): Al-bearing phyllosilicates are clearly present in the upper whitish outcrops, while nontronite is the dominant mineral of the red outcrops. It is important to note that the brownish unit underlying the reddish and whitish outcrops presents the lowest abundance of hydrated minerals and, correspondingly, the higher unaltered mafic concentration. Elsewhere in Mawrth Vallis, Table 1 indicates a total abundance greater than $50 \%$ for the hydrated minerals, phyllosilicate, and ferrihydrite, while the abundances of the primary minerals are lower than $\sim 30 \%$ with pyroxene phases modeled below the detection limit of 5-10\%. Iron-rich smectites were also detected in some Nili Fossae outcrops of the Noachian basement (Poulet et al. 2005; Mangold et al. 2007) (identified here as spots NF1 and NF2). The primary minerals dominate their modal mineralogy with abundance $>60 \%$. The rms error markedly improves if high-calcium pyroxene (and to a lesser degree low-calcium pyroxene) is included in the mixture, which indicates that pyroxene is present in these outcrops (Fig. 3). The modal mineralogy of the localized phyllosilicate deposits (spots O1-4) is also dominated by the primary minerals. Different phyllosilicate phases provide the best fit for each outcrop (kaolinite, $\mathrm{Mg}$-saponite, and hisingerite). The spectral modeling of the deposit NF3 associated with the central peak of the $40-\mathrm{km}$ sized crater reveals a unique composition (Fig. 4). The best satisfactory fit is obtained with the sorosilicate pumpellyite.

\section{Discussion and conclusion}

These modal analyses reveal major differences in the mineralogy of the selected outcrops. Mawrth Vallis has the largest abundance of hydrated minerals on Mars. The abundance and the nature of the anhydrous phases significantly differ in Nili Fossae suggesting a lower degree of alteration and/or a different process of alteration. Although these outcrops share some similarities with the Mawrth Vallis phyllosilicate-rich outcrops such as local layering, they also exhibit differences, such as the association with massive rocks and the presence of dikes and of possible volcanic landforms (Mangold et al. 2007). Hydrothermal fluid circulation was then proposed to be responsible for the alteration (Mangold et al. 2007). The other localized outcrops outside of the two largest sites have modal mineralogies dominated by primary minerals (pyroxenes and plagioclase) similar to Nili Fossae. In most of the phyllosilicate deposits (aside from those in the Mawrth Vallis region), the diverse suite of clay minerals and association of the clays with both primary minerals and complex igneous geomorphology point to a possible hydrothermal origin of the deposits. The alteration features could occur as vesicle and/or vein filling, and the various phyllosilicates (Fe/Mg/Alphases) may reflect the properties of the local fluids. Additional support for the formation process involving hydrothermal alteration in Nili Fossae comes from the recent CRISM observations revealing diverse phyllosilicates in this region (Mustard et al. 2008). 

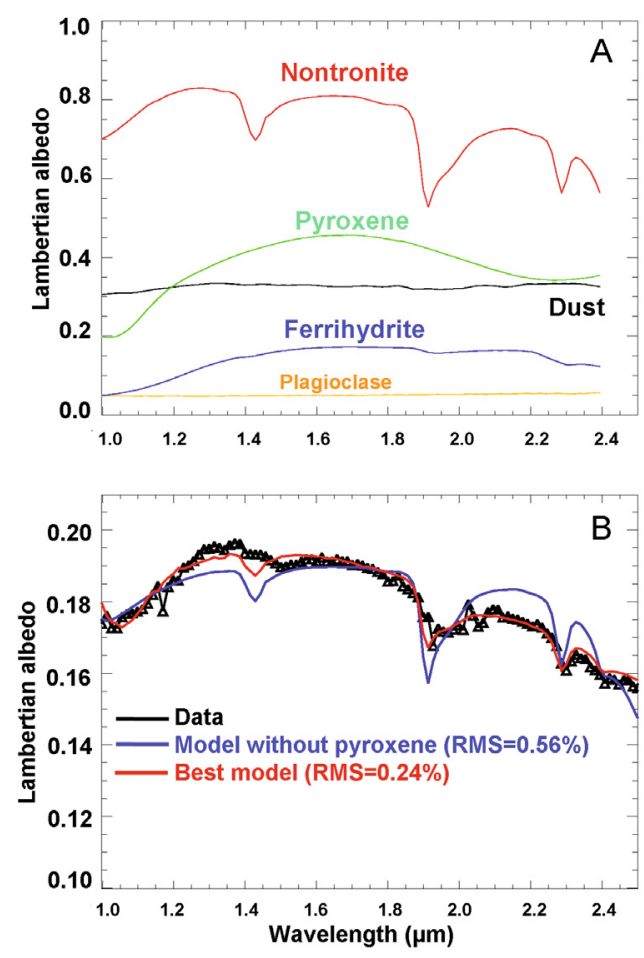

Fig. 3. Fit of a spectrum representative of the Noachian basement in Nili Fossae (spot NF1). A) Spectra of the end-members used for the modelings. B) The data spectrum (black line) is compared to the best-fit model (red line) and one model excluding the pyroxene as end-member (blue line).
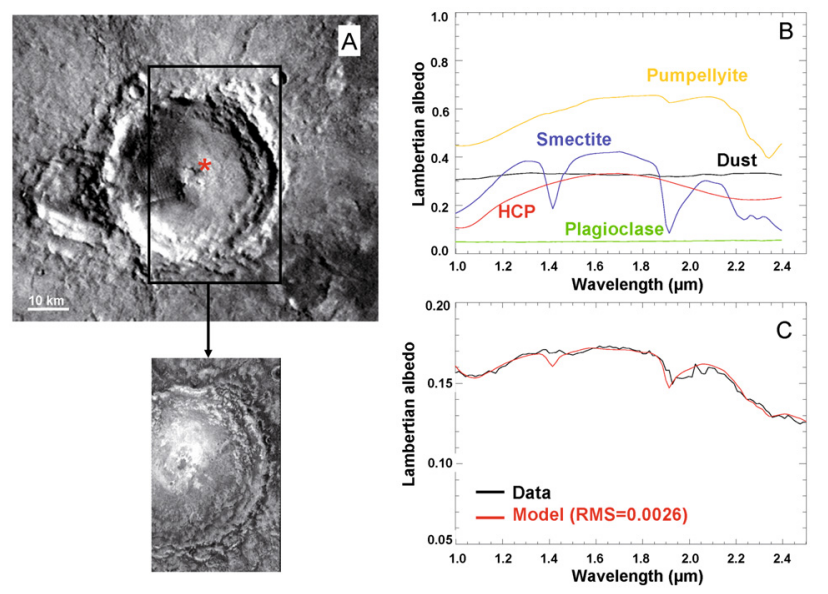

Fig. 4. Modal analysis of the deposit NF3 associated with the central peak of an impact crater centered at 17.0N, 71.8E. A) The red cross indicates the location over a Viking image for which the spectrum was extracted. A box delineates a portion of the infrared nighttime Thermal Emission Infrared Spectrometer (THEMIS) image I16829003 shown below the Viking image. The spectrum comes from a terrain with high brightness in the THEMIS image, indicating a relatively dust-free surface. B) Spectra of the end-members. C) Spectrum of NF3 deposit compared to its best fit.

The specific phyllosilicate enrichment of the central peak of a large crater may indicate an early impact, when water was present and phyllosilicate formed. However, the unique occurrence of pumpellyite provides evidence pre-existing rocks are recrystallized by changes in heat and pressure. The origin of this metamorphism might be related to the impact that formed the crater, either by its pressure or heat or both. Alternatively, the impact central peak may have excavated materials from deep parts of the crust, where metamorphism forming pumpellyite could have occurred.

Ferrihydrite is required in many of the spectral models to reproduce the ferric band in $1.0-1.3 \mu \mathrm{m}$, to adjust the intensity of the $1.9 \mu \mathrm{m}$ band, and to reproduce the plateau-like right wing starting at $2.3 \mu \mathrm{m}$. Specific geochemical conditions have been proposed to explain the co-occurrence of ferrihydrite and phyllosilicates (Chevrier et al. 2007). Ferrihydrite could also be the result of a post-alteration process.

The low abundance of residual primary minerals is specific to the Mawrth Vallis sites. In contrast to the pyroxenes, the generally more stable and resistant plagioclase mineral seems to have partly survived through the alteration process. Nontronite, the most abundant smectite in this region, can be a common and dominant weathering product near the weathering front in saprolites on basic and ultrabasic rocks (Velde 1995). Other phyllosilicates (illite, montmorillonite, kaolinite) that are the products of the alteration of previous rock-forming minerals of any type are definitely present. The presence of kaolinite could indicate an active hydrologic system with good drainage and high solubility (Velde 1995; Chevrier et al. 2007). We find that the Al- and Fesmectites occur in two types of spatially distinct stratigraphic sub-units (identified as the whitish and reddish units in Fig. 2) that are exposed at the top of a unit (brown unit) that contains only a small fraction of hydrated minerals. The large amount of clays coupled to their geological settings within layers deposited above a less altered surface (the brown basal unit) shows that the material experienced alteration at the surface, or close to the surface, in contrast to Nili Fossae where the alteration may have occurred at greater depth and higher temperatures.

Acknowledgements. This work was supported by the French space agency CNES, CNRS, and Université Paris-Sud. We thank Dr. Fonti for his useful comments.

\section{References}

Arvidson, R. E., Poulet, F., Morris, R. V., et al. 2006, J. Geophys. Res., 111, 10.1029/2006JE002728

Chevrier, V., Poulet, F., \& Bibring, J.-P. 2007, Nature, 7149, 60

Cloutis, E. A., Craig, M. A., Mustard, J. F., et al. 2007, Geophys. Res. Lett. 34, 10.1029/2007GL031267

Cloutis, E. A., Craig, M. A., Kruzelecky, R. V., et al. 2008, Icarus, 195, 140

Cooper, C. D., \& Mustard, J. F. 1999, Icarus 142, 557

Langevin, Y., Bibring, J.-P., Montmessin, F., et al. 2007, J. Geophys. Res., 112, 10.1029/2006JE002841

Loizeau, D., Mangold, N., Poulet, F., et al. 2007, J. Geophys. Res., 112, 10.1029/2006JE002877

Loizeau, D., Mangold, N., Poulet, F., et al. 2008, J. Geophys. Res. submitted

Mangold, N., Poulet, F., Mustard, J. F, et al. 2007, J. Geophys. Res., 112, 10.1029/2006JE002835

Michalski, J. R., Fergason, R., Noe Dobrea, E. Z., et al. 2007, 7th Mars Conference abstract, 3036

Mustard, J. F., Murchie, S. L., Ehlmann, B. L., et al. 2008, Nature, in press

Poulet, F., \& Erard, S. 2004, J. Geophys. Res., 109, 10.1029/2003JE002179

Poulet, F., Cuzzi, J. N., Cruikshank, D. P., Roush, T., \& Dalle Ore, C. M. 2002, Icarus, 160,313

Poulet, F., Mangold, N., \& Erard, S. 2003, A\&A, 412, L19

Poulet, F., Bibring, J.-P., Mustard, J. F., et al. 2005, Nature, 438, 623

Roush, T., Esposito, F., Rossman, G. R., \& Colangeli, L. 2007, J. Geophys. Res. 112, 10.1029/2007JE002920

Shkuratov, Y., Starukhina, L., Hoffmann, H., \& Arnold, G. 1999, Icarus, 137, 235

Velde, B. 1995, Origin and Mineralogy of Clays (Berlin: Springer) 
F. Poulet et al.: Quantitative mineralogy of Martian phyllosilicate-rich terrains, Online Material p 1

Table 1. Derived modal mineralogy of the studied phyllosilicate-rich outcrops. Values are percent and are rounded to 5\%. The abbreviated names of minerals are: Nont: Nontronite, Mont: Montmorillonite, Kaol: Kaolinite, Ferri: Ferrihydrite, Pump: Pumpellyite, Hi: Hisingerite, Plag: Plagioclase, Pyr: Pyroxene.

\begin{tabular}{|c|c|c|c|c|c|c|c|c|c|c|c|c|c|c|}
\hline Spot & Location $^{1}$ & Nont & Mont & Kaol & Ferri & Smectite $^{2}$ & Pump & Mg-Saponite & $\mathrm{Hi}$ & Illite & Plag & Dust & Pyr & $\mathrm{rms}$ \\
\hline & Mawrth Vallis & & & & & & & & & & & & & \\
\hline MV1 & $341.64,21.90$ & 50 & - & - & 15 & - & - & - & - & - & 20 & 13 & - & 0.0031 \\
\hline MV2 & $342.45,23.24$ & 65 & - & - & 10 & - & - & - & - & - & 15 & 10 & - & 0.0028 \\
\hline MV3 & $341.48,23.03$ & 20 & - & - & 20 & - & - & - & - & - & 30 & 30 & - & 0.0019 \\
\hline MV4 & $341.22,24.08$ & 40 & - & - & 20 & - & - & - & - & - & 25 & 10 & - & 0.0026 \\
\hline MV5 & $341.05,24.74$ & 40 & - & - & 20 & - & - & - & - & - & 30 & 5 & - & 0.0020 \\
\hline MV6 & $340.83,26.50$ & 50 & - & - & 15 & - & - & - & - & - & 20 & 15 & - & 0.0027 \\
\hline MV7 & $338.80,24.59$ & - & 20 & 20 & 25 & - & - & - & - & - & 25 & 5 & - & 0.0029 \\
\hline MV8 & $338.87,24.39$ & 55 & - & - & 10 & - & - & - & - & - & 25 & 5 & 5 & 0.0021 \\
\hline MV9 & $338.80,24.30$ & 25 & - & - & 20 & - & - & - & - & - & 35 & 5 & 15 & 0.0019 \\
\hline MV10 & $\begin{array}{l}338.80,24.44 \\
\text { Nili Fossae }\end{array}$ & 50 & - & - & 5 & - & - & - & - & 15 & 20 & 10 & - & 0.0023 \\
\hline NF1 & $73.08,19.54$ & 20 & - & - & - & - & - & - & - & - & 50 & 10 & 20 & 0.0027 \\
\hline NF2 & $73.40,23.04$ & 5 & - & - & 30 & - & - & - & - & - & 45 & - & 20 & 0.0020 \\
\hline NF3 & $\begin{array}{l}71.83,17.10 \\
\text { Other deposits }\end{array}$ & - & - & - & - & 15 & 20 & - & - & - & 40 & 15 & 20 & 0.0026 \\
\hline $\mathrm{O} 1$ & $354.53,-5.02$ & - & - & - & 15 & - & - & 15 & - & - & 50 & - & 20 & 0.0024 \\
\hline $\mathrm{O} 2$ & $305.52,18.80$ & - & 5 & - & 20 & - & - & 20 & - & - & 35 & 5 & 15 & 0.0027 \\
\hline $\mathrm{O} 3$ & $90.46,-4.32$ & - & - & - & 10 & - & - & - & 35 & - & 35 & 5 & 15 & 0.0023 \\
\hline $\mathrm{O} 4$ & $202.25,-30.62$ & - & 15 & 10 & - & - & - & - & - & - & 45 & 5 & 25 & 0.0027 \\
\hline
\end{tabular}

${ }^{1}$ Longitude $\left({ }^{\circ} \mathrm{E}\right)$, Latitude $\left({ }^{\circ} \mathrm{N}\right) ;{ }^{2} \mathrm{Al} / \mathrm{Mg} / \mathrm{Fe}$-bearing smectite. 